NASA/TM-2006-214220

IECEC-2005-5576

NASA

$+\cdots$

\title{
Fabrication Materials for a Closed Cycle Brayton Turbine Wheel
}

\author{
Suresh Khandelwal
}

RS Information Systems, Inc., Cleveland, Ohio

Chunill Hah

Glenn Research Center, Cleveland, Ohio

Lynn M. Powers

Case Western Reserve University, Cleveland, Ohio

Mark E. Stewart and Ambady Suresh

QSS Group, Inc., Cleveland, Ohio

Albert K. Owen

U.S. Army Research Laboratory, Glenn Research Center, Cleveland, Ohio 


\section{NASA STI Program . . . in Profile}

Since its founding, NASA has been dedicated to the advancement of aeronautics and space science. The NASA Scientific and Technical Information (STI) program plays a key part in helping NASA maintain this important role.

The NASA STI Program operates under the auspices of the Agency Chief Information Officer. It collects, organizes, provides for archiving, and disseminates NASA's STI. The NASA STI program provides access to the NASA Aeronautics and Space Database and its public interface, the NASA Technical Reports Server, thus providing one of the largest collections of aeronautical and space science STI in the world. Results are published in both non-NASA channels and by NASA in the NASA STI Report Series, which includes the following report types:

- TECHNICAL PUBLICATION. Reports of completed research or a major significant phase of research that present the results of NASA programs and include extensive data or theoretical analysis. Includes compilations of significant scientific and technical data and information deemed to be of continuing reference value. NASA counterpart of peer-reviewed formal professional papers but has less stringent limitations on manuscript length and extent of graphic presentations.

- TECHNICAL MEMORANDUM. Scientific and technical findings that are preliminary or of specialized interest, e.g., quick release reports, working papers, and bibliographies that contain minimal annotation. Does not contain extensive analysis.

- CONTRACTOR REPORT. Scientific and technical findings by NASA-sponsored contractors and grantees.
- CONFERENCE PUBLICATION. Collected papers from scientific and technical conferences, symposia, seminars, or other meetings sponsored or cosponsored by NASA.

- SPECIAL PUBLICATION. Scientific, technical, or historical information from NASA programs, projects, and missions, often concerned with subjects having substantial public interest.

- TECHNICAL TRANSLATION. Englishlanguage translations of foreign scientific and technical material pertinent to NASA's mission.

Specialized services also include creating custom thesauri, building customized databases, organizing and publishing research results.

For more information about the NASA STI program, see the following:

- Access the NASA STI program home page at http://www.sti.nasa.gov

- E-mail your question via the Internet to help@sti.nasa.gov

- Fax your question to the NASA STI Help Desk at 301-621-0134

- Telephone the NASA STI Help Desk at 301-621-0390

- Write to:

NASA STI Help Desk

NASA Center for AeroSpace Information 7121 Standard Drive Hanover, MD 21076-1320 
NASA/TM-2006-214220

IECEC-2005-5576

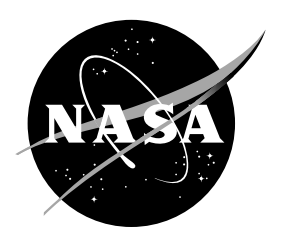

\section{Fabrication Materials for a Closed Cycle Brayton Turbine Wheel}

Suresh Khandelwal

RS Information Systems, Inc., Cleveland, Ohio

Chunill Hah

Glenn Research Center, Cleveland, Ohio

Lynn M. Powers

Case Western Reserve University, Cleveland, Ohio

Mark E. Stewart and Ambady Suresh

QSS Group, Inc., Cleveland, Ohio

Albert K. Owen

U.S. Army Research Laboratory, Glenn Research Center, Cleveland, Ohio

Prepared for the

Third International Energy Conversion Engineering Conference (IECEC)

sponsored by the American Institute of Aeronautics and Astronautics

San Francisco, California, August 15-18, 2005

National Aeronautics and

Space Administration

Glenn Research Center

Cleveland, Ohio 44135 


\section{Acknowledgments}

NASA's Prometheus Nuclear Systems Program supported the work described within this paper, in whole or part, as part of the program's technology development and evaluation activities.

This report contains preliminary findings, subject to revision as analysis proceeds.

Level of Review: This material has been technically reviewed by technical management.

Available from

NASA Center for Aerospace Information 7121 Standard Drive

Hanover, MD 21076-1320
National Technical Information Service 5285 Port Royal Road Springfield, VA 22161

Available electronically at http://gltrs.grc.nasa.gov 


\title{
Fabrication Materials for a Closed Cycle Brayton Turbine Wheel
}

\author{
Suresh Khandelwal \\ RS Information, Systems Inc. \\ Cleveland, Ohio 44135 \\ Chunill Hah \\ National Aeronautics and Space Administration \\ Glenn Research Center \\ Cleveland, Ohio 44135 \\ Lynn M. Powers \\ Case Western Reserve University \\ Cleveland, Ohio 44106 \\ Mark E. Stewart and Ambady Suresh \\ QSS Group, Inc. \\ Cleveland, Ohio 44135 \\ Albert K. Owen \\ U.S. Army Research Laboratory \\ Glenn Research Center \\ Cleveland, Ohio 44135
}

\begin{abstract}
A multidisciplinary analysis of a radial inflow turbine rotor is presented. This work couples high-fidelity fluid, structural, and thermal simulations in a seamless multidisciplinary analysis to investigate the consequences of material selection. This analysis extends multidisciplinary techniques previously demonstrated on rocket turbopumps and hypersonic engines. Since no design information is available for the anticipated Brayton rotating machinery, an existing rotor design (the Brayton Rotating Unit (BRU)) was used in the analysis. Steady state analysis results of a notional turbine rotor indicate that stress levels are easily manageable at the turbine inlet temperature, and stress levels anticipated using either superalloys or ceramics.
\end{abstract}

\section{Introduction}

Because of their relatively high power density, advanced, closed cycle Brayton power units are candidates for future NASA Exploration missions. In combination with a nuclear reactor, they can provide in-space and surface power as well as power for electric propulsion. One of the future in-space power applications is the Prometheus nuclear power plant (200 KW power class), and a proposed mission is a long duration deep-space craft whose missions will likely focus on voyages to the outer planets.

The baseline configuration for the Brayton unit of this power plant uses a radial inflow turbine fabricated from a superalloy material. One trade study is a turbine material change from a superalloy to a Silicon Nitride ceramic.

Since the cycle and design have not been finalized, a previous design, the NASA Brayton Rotating Unit (BRU), was selected for this preliminary study. This paper provides a detailed description of the resulting analysis.

The consequences of a turbine material change are quantified in this paper through the use of high-fidelity, three-dimensional, and multidisciplinary simulation techniques. These simulation techniques provide detailed information about the test article including pressure and temperature distributions, centrifugal loads, surface deflections including blade tip clearance, and thermal expansion. Although, numerical simulations do not replace experimental testing, they do provide design insights that reduce the risk and cost of a development program. Numerical simulations do this by allowing design variations to be considered quickly and inexpensively.

The Numerical Propulsion Systems Simulation (NPSS) project developed and demonstrated techniques and software that allow a closely coupled, three-dimensional, fluid-structural-thermal analysis. The approach uses well validated fluid and structural analysis codes coupled together so that the correct physical boundary conditions are satisfied at the fluid-solid interfaces. Demonstrations of this capability include a rocket engine turbopump (ref. 1) and a hypersonic engine (ref. 2). This paper describes the application of these techniques, using H3D and ANSYS, to analyze forces on a notional Prometheus turbine rotor and the resultant stress and deformation field.

The following sections describe the Brayton radial turbine, the numerical methods and multidisciplinary coupling techniques, the considerations for superalloy and ceramic materials, and results. 


\section{The Brayton Rotating Unit (BRU)}

The Brayton Rotating Unit (ref. 3) was designed, built, and tested by AiResearch Manufacturing Company for NASA Glenn Research Center in the mid-1960's. Detailed design information and hardware is readily available for use in comprehensive simulations. Further, the Prometheus Brayton unit is expected to have similar cycle, working fluid, flow rates, and temperatures to those of the well characterized BRU.

Figure 1 shows the structural model for one blade passage (blade+inlet splitter) of the BRU turbine rotor and specifications are listed in table 1 . Also listed in table 1 are the approximate specifications for a notional Prometheus turbine configuration. Notice the similarity in flow rates, pressure ratios and turbine inlet temperatures.

However, in the 40 years since the BRU's design, radial turbine technology has advanced, and a modern design would have some differences. For example, the BRU was designed with splitter blades in addition to the main blades; current design experience suggests that splitter blades offer little, if any, advantage. Further, current designs include "scalloped" cutouts of the rotor hub between the blades in the high radius section near the inlet. Removing material in this high radius region tends to reduce high centrifugal loads.

Due to different requirements and modern design techniques, differences are likely between the final Prometheus turbine design and the BRU turbine. Consequently, additional analysis of the final design may be necessary to insure the validity of the current conclusions. Further, a major goal of this effort has been the identification of actual and potential problems and their elimination.

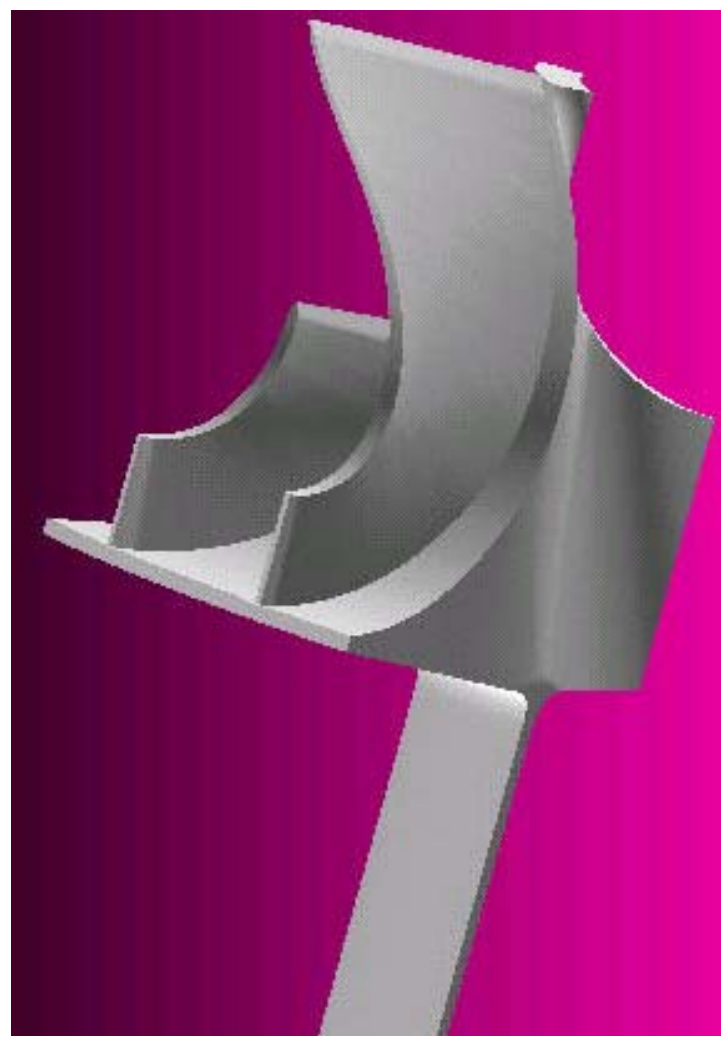

Figure 1.- Structural model for one bladepassage (blade+splitter) of the BRU's radial inflow torrhine.

TABLE 1.-COMPARISON BETWEEN THE BRU TURBINE AND NOTIONAL PROMETHEUS TURBINE

\begin{tabular}{|l|c|c|c|}
\hline & & BRU & Prometheus \\
\hline Number of blades & & 11 & 15 \\
\hline Number of splitters & & 11 & 0 \\
\hline Inlet diameter & $\mathrm{Cm}(\mathrm{In})$ & $12.63(4.974)$ & $\sim 15.6(6.141)$ \\
\hline Exit tip radius & $\mathrm{Cm}(\mathrm{In})$ & $8.79(3.462)$ & $\sim 78000$ \\
\hline Rotational speed & $\mathrm{RPM}$ & 36000 & $\sim 2.245(4.95)$ \\
\hline Corrected mass flow rate & $\mathrm{Kg} / \mathrm{Sec}(\mathrm{Lbm} / \mathrm{Sec})$ & $0.598(1.318)$ & $\sim 1.72$ \\
\hline Pressure ratio & & 1.56 & $1150(2070)$ \\
\hline Rotor inlet temperature & $\mathrm{Deg} \mathrm{K}(\mathrm{R})$ & $1144(2060)$ & In $792(5 \mathrm{~A})$ \\
\hline Material & & In 713C & HeXe mixture \\
\hline Operating fluid & & Argon & \\
\hline
\end{tabular}

\section{Superalloy and Ceramic Materials}

One proposed mission for the Prometheus space nuclear power plant is a long duration deep-space craft whose missions will likely focus on voyages to the outer planets. Such missions impose unique and challenging requirements on the vehicle and its power systems including rigorous demands on durability and reliability. A deep space mission may last 15 years. Designers must insure that unexpected shocks, material changes (due, perhaps, to radiation), vehicle accelerations (planned and unplanned), changes in modes of operation, or other events do not result in the insertion of debris into the closed system. Possible changes on the operating speeds or the necessity to start a spare power unit after a long delay may also be a consideration. And, of course, competing and contradictory mission requirements such as system efficiency, weight and volume considerations, vibration restrictions, and power system flexibility force difficult design decisions. 
Ni-based superalloys are the standard material choice for high temperature turbine applications. However, in a space power application where starts and stops are minimal and the mission life long; sustained load or creep deformation will become a dominant concern, particularly for metallic superalloys at temperatures above $600{ }^{\circ} \mathrm{C}$. Of course, the particular application limit will be a function of alloy, temperature, and stress. This deformation can lead to noticeable changes in performance and, in a worst case scenario, blade rubs or failure. In addition, the practical upper limit of modern superalloys is roughly $1200{ }^{\circ} \mathrm{C}$, thus limiting system efficiency. However, superalloys have been used successfully for decades in rotating machinery and relatively easily machined into aerodynamically efficient shapes. Thus there exists a broad historical design base from which to draw.

Up to 1150 to $1200^{\circ} \mathrm{C}$, silicon nitride, a ceramic material, does not experience traditional creep deformation or strength loss. Thus there is opportunity for higher cycle temperatures and, as a result, higher efficiencies. Silicon Nitride parts are only $40 \mathrm{wt} \%$ of an equivalent superalloy blade, thus providing a significant weight savings. Nonetheless, they can place restrictions on turbine design due to blade thickness and mating with metallic materials. However, the most serious concern with ceramic materials is the life issue; ceramics can suffer from slow crack growth in the temperature regimes of interest here. Yet, the technological benefits of implementing a silicon nitride wheel warrant further scrutiny, as demonstrated in the subsequent analysis.

\section{The Multidisciplinary Analysis}

The objective of a multidisciplinary simulation is to accurately capture the interactions between discipline solutions - for example, the effect of thermal expansion on blade tip clearance. To capture multidisciplinary interactions, the analysis must provide a seamless and consistent solution throughout the flow domain. Here, this goal is achieved by developing component solutions and devising boundary conditions which ensure that aerodynamic pressures are transferred to structural loads, temperatures, and heat fluxes are continuous at fluid-solid interfaces, and the deflected walls are the same as the fluid boundary.

The following sections describe the three-dimensional, aerodynamics and structural/thermal analysis codes, as well as how these codes are coupled.

\section{A. The Fluid Flow Analysis}

The current study used a three-dimensional, unsteady, Navier-Stokes code (H3D) that has been developed and validated on various turbomachinery flows (refs. 4 and 5). This software was selected primarily for its maturity, robustness, and flexibility (it will model splitter blades). In addition, its use in a previous project (ref. 1) for multidisciplinary analysis minimized any "research development" work and allowed the team to concentrate on the rotor structural analysis with some technology maturation.

Previous studies (refs. 5 and 6) have shown that high-order discretization schemes are necessary in both space and time to avoid excessive numerical dissipation. Therefore, a third-order accurate interpolation scheme is used for the spatial discretization of the convection terms and central differencing is used for the diffusion terms. The method yields second-order spatial accuracy on smoothly varying grids.

An implicit, second-order scheme is used for time integration. For unsteady flow calculations, the size of the time step is primarily determined by the requirement for physical accuracy. However, the time step is also restricted by numerical stability. The current implicit time integration approach performs a sub-iteration at each time step to ensure stability and accuracy over a range of physical time steps. The residuals of each finite difference equation are integrated over the entire flow domain at each sub-iteration. When the integrated residuals have been reduced by four orders of magnitude from their initial values, the solution is advanced to the next time step.

The computational grid describing the BRU radial turbine is shown in figure 2 . The grid for a single blade passage consists of 60 nodes in the blade-to-blade direction, 40 nodes in the spanwise direction, and 120 nodes in the streamwise direction. The rotor tip gap was represented with 6 nodes in the spanwise direction. As the primary objective of the flow analysis was to obtain blade loading, a relatively coarse grid was applied. The calculated pressure distribution and velocity vector at 15 percent blade height from hub are shown in figures 3 and 4 . Figures 5 and 6 show the calculated pressure distribution and velocity vectors inside tip gap.

At the inlet of the computation domain, the velocity components are specified. At the exit of the computational domain, constant streamwise gradients of the variables are assumed and total mass conservation is imposed. A modified two-equation model with near wall corrections is used to estimate turbulence stresses. 


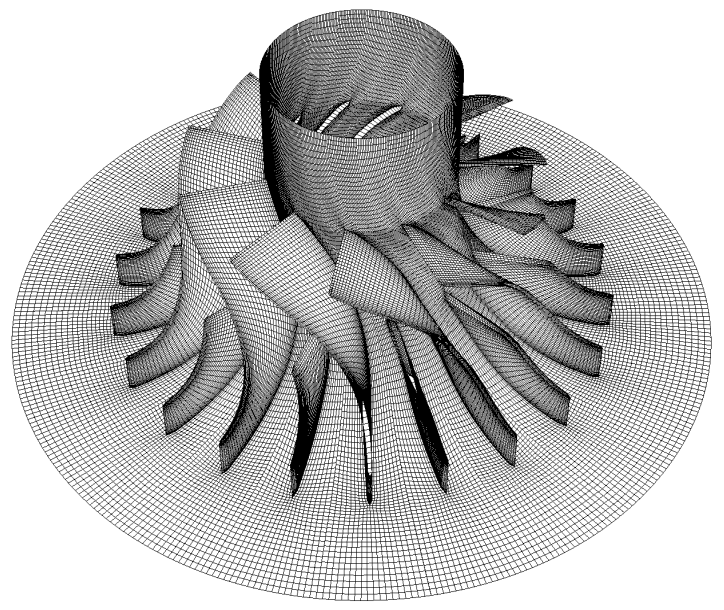

Figure 2.-Navier-stokes computational grid.

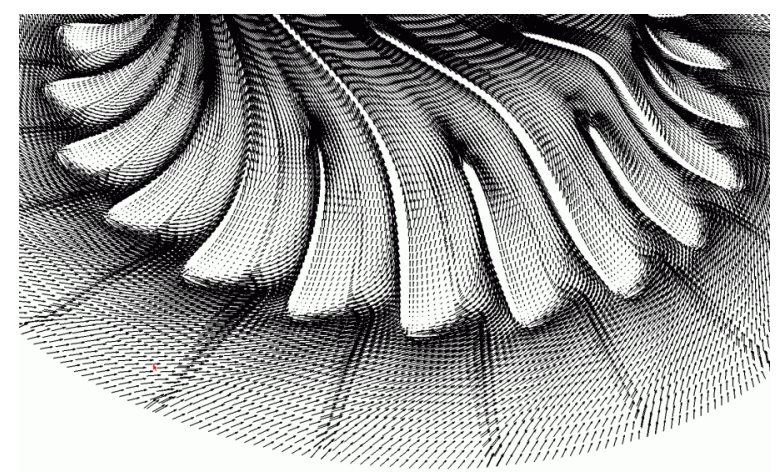

Figure 4.-Near hub fluid velocity field.

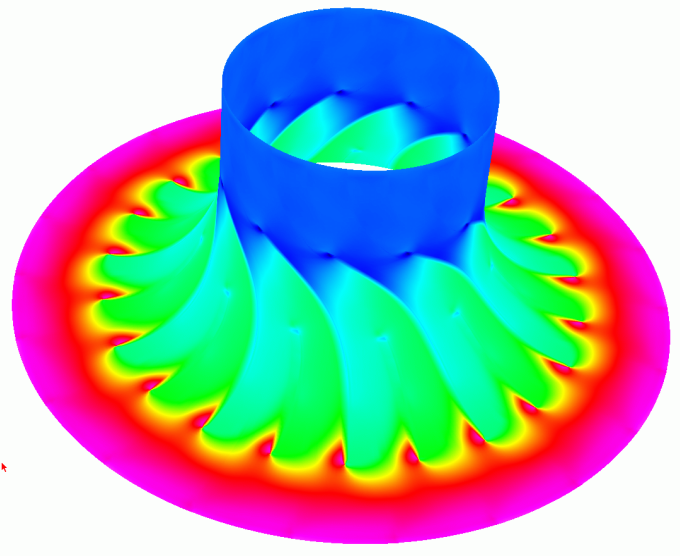

Figure 3.-Near hub fluid pressure field.

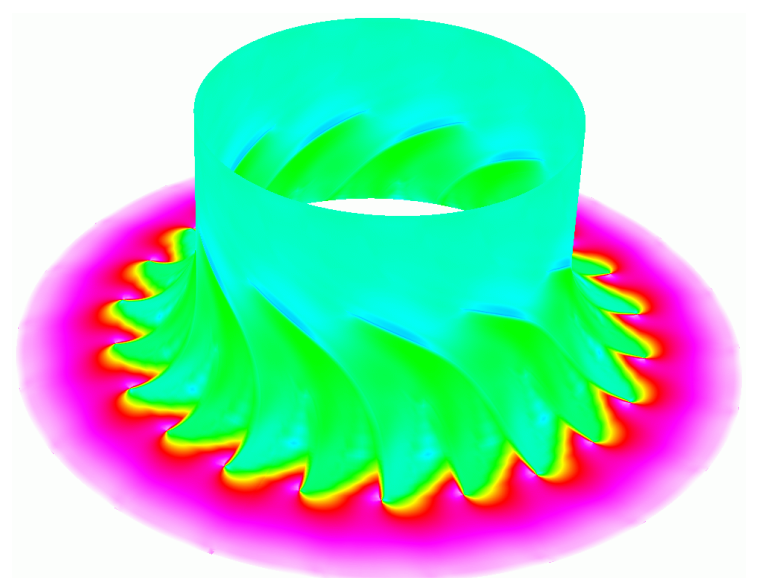

Figure 5.- Near shroud fluid pressure field.

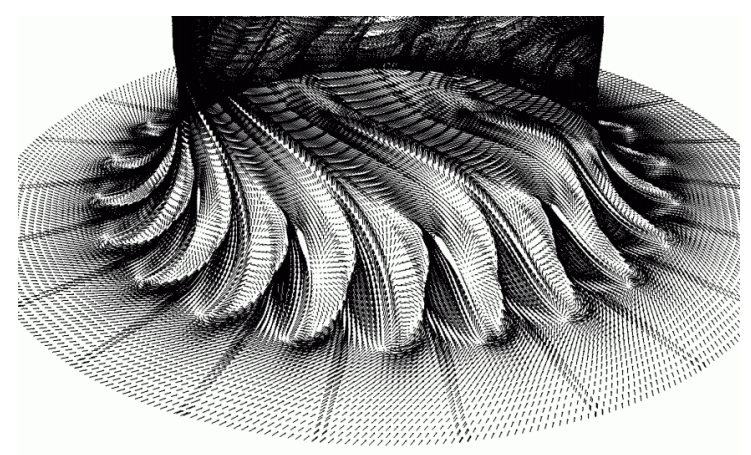

Figure 6.-Near shroud fluid velocity field. 


\section{B. The Structural Analysis}

The structured grids for the rotor blades were generated from the fluid grids. Nodes on the blade leading and trailing edges were partitioned so as to obtain a reasonable hexahedral grid in the interior of the blade. At the leading and trailing edges of the blade, the hexahedral elements degenerate into prisms. Since the structural and fluid nodes are coincident on the blade surface, no interpolation is necessary when transferring loads from the fluid analysis.

It is necessary to include the hub disk in the structural analysis. Figure 7 shows the structural grid surface used in this analysis. In addition, the structural analysis must include additional features sometimes neglected in the aero analysis, including finite curvature fillets used to reduce stress concentrations near the hub surface. These elements are gridded separately from the blades using GRIDGEN and joined to the blade grid.

The structural studies were done with ANSYS (Version 9.0), a program based on finite element analysis. The process begins with an output file from the CFD solution containing grid coordinates and pressure values at each grid point. A program was written to translate the grid and pressure data to appropriate formats to be read by ANSYS. Elements for the model were defined by the connectivity between nodes. A SOLID45 element type was chosen with 8-node connectivity and 3 degrees of freedom. Each element is defined in terms of 8 nodes, labeled I, J, $\mathrm{K}, \mathrm{L}, \mathrm{M}, \mathrm{N}, \mathrm{O}$, and P, as discussed in the ANSYS Programmer's Manual (ref. 7). The node coordinates and element connectivity data for each blade were written to files in the ANSYS format. The pressure at each grid point was transferred from the CFD solution file. The pressures for each blade were then written to a file using the ANSYS format. All of the calculations were done on an SGI computer running under IRIX 6.5.

\section{Multidisciplinary Coupling}

Surface pressure loads from the fluid analysis were imported into ANSYS, applied to the model, and the resultant stress and deformation fields calculated. These fields were then used to identify any structural concerns should there be a material change.

The fluid flow code (H3D) and the structural code (ANSYS) were coupled to perform a combined FluidStructural analysis. The coupling was achieved by creating an NPSS model. NPSS is a product developed at NASA Glenn. The NPSS environment allows users to create servers (local or remote) whose locations are identified by script parameters. Each server is connected to an external component where a part of the model is executed. Figure 8 illustrates the coupling of the CFD code (H3D) and the structure code (ANSYS). For this study, four servers (CFD, MODEL, ANSYS, and GRIDUPD) were defined for the coupled execution. The CFD server is a CORBA server, where the fluid code is executed. The MODEL server is used to create the files to be used for structural analysis from the data obtained from the fluid analysis. The structural analysis is performed at the ANSYS server and updating of grid data is done at GRIDUPD. The data transfer is done using the file transfer option available under NPSS. In figure 8, the ovals represent programs and the rectangles represent data being passed between programs. NPSS script controls the sequence of programs to be executed.

The multidisciplinary analysis can predict the tip clearance change between the "cold" and "hot" metal shapes. This shape change is dominated by thermal expansion; centrifugal effects also contribute to tip clearance changes, but pressure loads have a small effect.

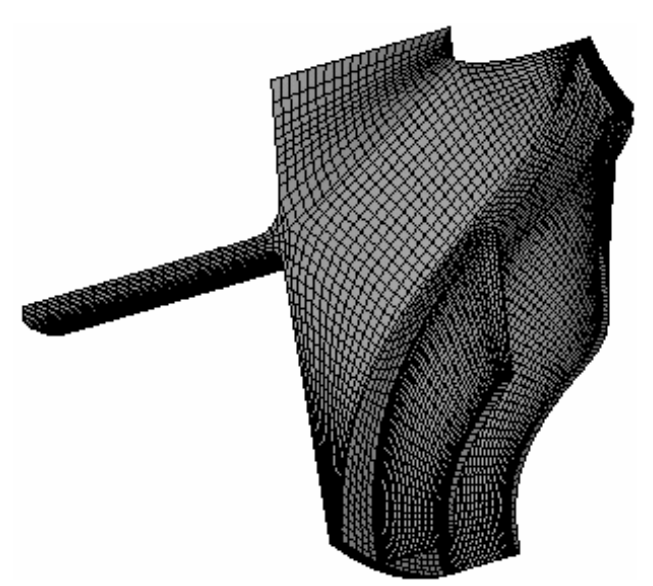

Figure 7.-ANSYS grid of single blade passage for MDC analysis.

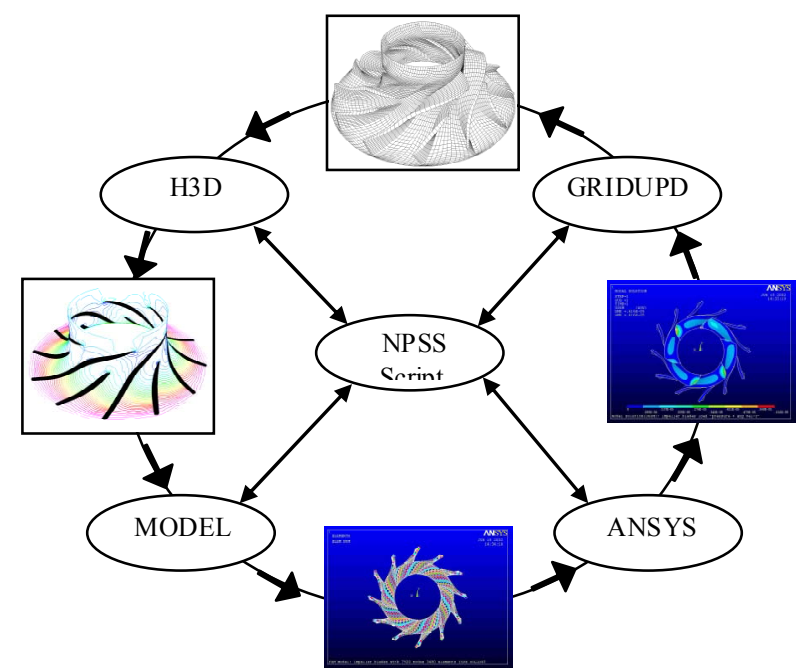

Figure 8.-Logic diagram for closely coupled MDC analysis. 


\section{The Feasibility of Ceramic Materials}

Research done as early as the 1950s (ref. 8) has indicated that a simple one-to-one change of materials from metal to ceramic is not a feasible approach to ceramic insertion into turbomachinery. Problems of contact stresses at the blade attachment points, thermal shock resistance, stress rupture life, and ceramic oxidation resistance were shown to be principal issues. The problems of rupture life and oxidation resistance have proven tractable to improved processing methods and environmental barrier coatings. However, attachment issues, particularly contact stresses, remain difficult to address. In this Prometheus trade study other potential difficulties include adequate long life reliability of ceramic components, and proper design of rotating components to meet clearance specifications.

Given these concerns, one of the authors completed a steady state analysis at the BRU rotor design condition based on the multidisciplinary ANSYS and H3D results. Figures 9 (superalloy) and 10 (ceramic) show the von Mises and the maximum principal stresses for the superalloy and silicon nitride, respectively. These stresses are critical for each material. Temperatures on this rotor are not high and no material change would be necessary. However, the ANSYS analysis was run with Silicon Nitride and figure 11 shows the area of greatest rupture

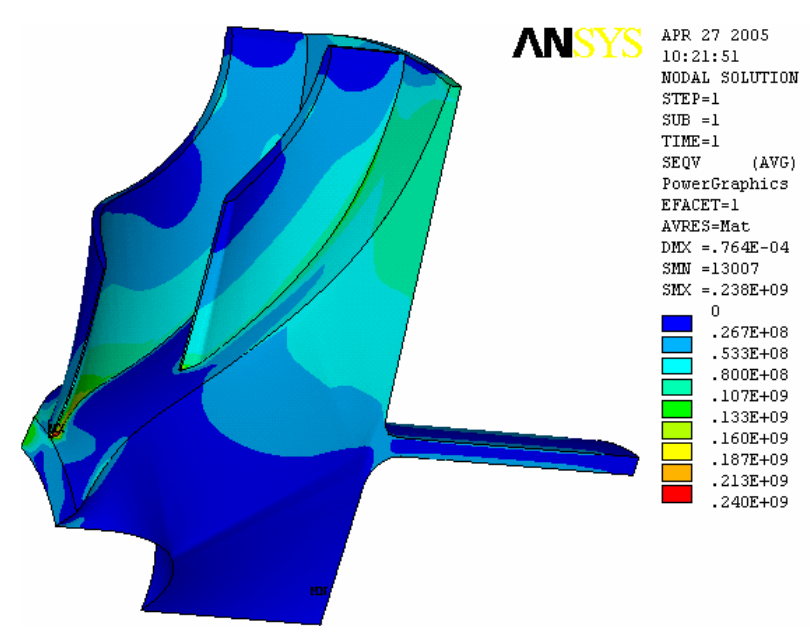

Figure 9.- Stress profile for inconel 793 rotor with $\max$ seq $=238 \mathrm{E} 6 \mathrm{psi}$.

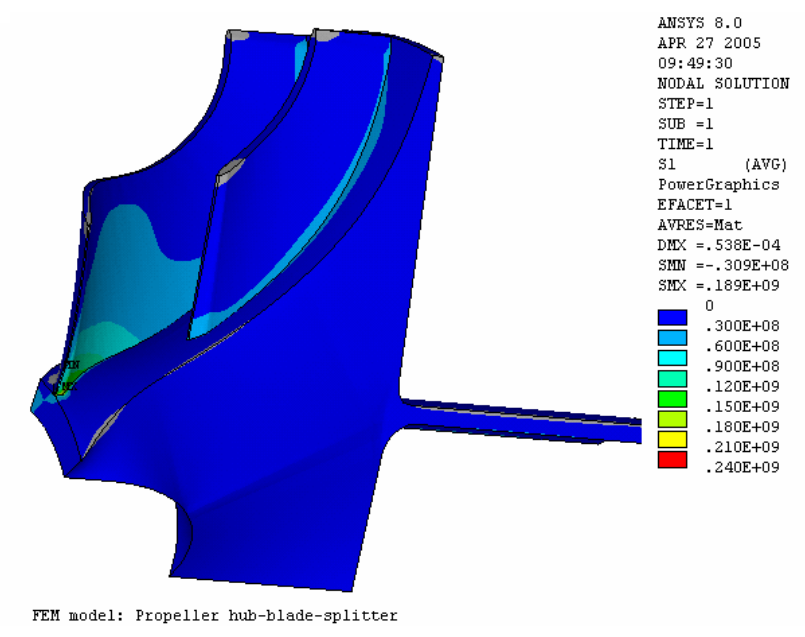

Figure 10.- Stress profile for silicon nitride rotor with max s1 $=189 \mathrm{E} 6 \mathrm{psi}$.
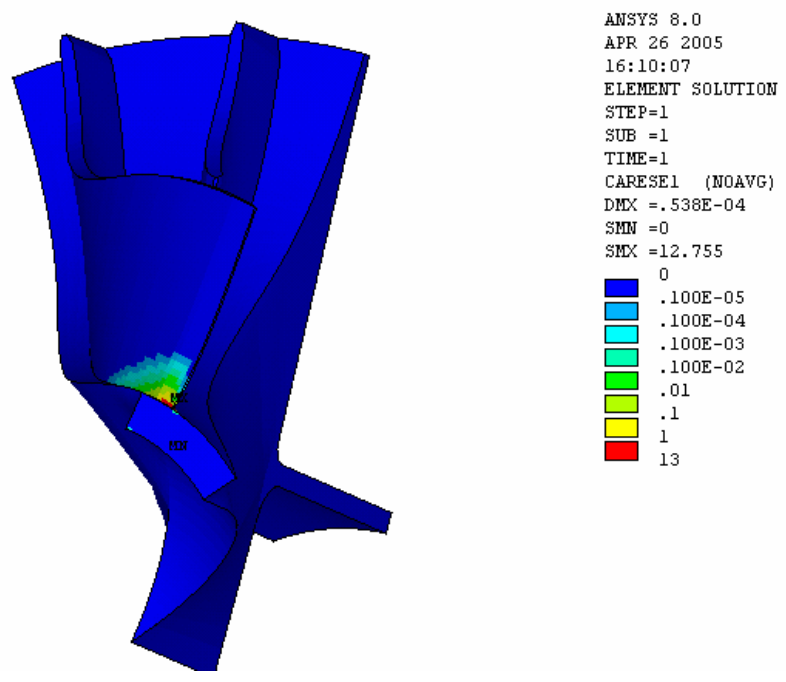

Figure 11.-Risk of rupture intensity. 
intensity as calculated by the Ceramics Analysis and Reliability Evaluation of Structures Life Prediction Program (CARES/LIFE). This area is at the hub/trailing edge intersection and has a risk of rupture intensity of 13. Rupture intensity, the probability of failure/volume, may be thought of as a failure probability density. The value of 13 is a function not only of failure probability but of the element size - which is very small in this region. Thus, this result shows where the failure would most likely occur but not the actual probability of failure. These results suggest modifying the fillet design in the hub/trailing edge region. Notice in table 2 that the probability of failure, even after 10 years of operation is less than 1 in 2.5 million. Clearly, the likelihood of failure of a ceramic component in this shape is extremely small.

TABLE 2.-FAILURE PROBABILITY OF BRU TURBINE ROTOR

\begin{tabular}{|c|c|}
\hline Time in service & Probability of failure \\
\hline 0 & $5.926 \times 10^{-12}$ \\
\hline 1 month (30 days) & $1.324 \times 10^{-8}$ \\
\hline 1 year & $7.696 \times 10^{-8}$ \\
\hline 10 years & $3.923 \times 10^{-7}$ \\
\hline
\end{tabular}

\section{Summary and Conclusions}

This paper presents the results a coupled fluid/structural analysis of the Brayton Rotating Unit turbine wheel. This analysis was done to mature the coupling technology in preparation of an analysis of the Prometheus closed Brayton cycle turbine wheel and to provide a exploratory study of the implementation issues that might be incurred if a material change is considered for the Prometheus turbine wheel.

The coupled analysis method required more human intervention than desired but provided a significant improvement in time of analysis and results by requiring a closer and more complete transfer of data between fluid and structural codes and by reducing human interaction during the process. Steady state analysis of the BRU turbine rotor indicates that failure of a Silicon Nitride rotor, at the provided cycle operating point is extremely unlikely. From that perspective, a material substitution should not be an issue.

This analysis does not address possible contact stresses and blade rubbing issues and the results are not meant to suggest that a one-to-one substitution is a feasible approach. However, the low probability of failure predicted for the silicon nitride wheel at the highest fluid-induced stress location does suggest that a properly redesigned rotor could be successful.

\section{References}

1. Hah, J. Loelbach, S. Khandelwal, T.M. Lavelle, "Multidisciplinary Coupling Analysis of Pump Stages for Space Propulsion Systems," ISABE 2003-1164.

2. M.E.M. Stewart, A. Suresh, M.S. Liou, A.K. Owen, D.G. Messitt, "Multidisciplinary Analysis of a Hypersonic Engine," AIAA Paper 2002-5127.

3. "Design and Fabrication of a High-Performance Brayton Cycle Radial-Flow Gas Generator," AiResearch Manufacturing Company, Phoenix AZ, NASA CR-706, (February, 1967).

4. C. Hah, S.L. Puterbaugh, and W.W. Copenhaver, "Unsteady Aerodynamic Phenomena in A Transonic Compressor Stage," AIAA Paper 93-1868, 1993.

5. Lee, Y., Hah, C., and Loellbach, J., "Unsteady Flow Interaction Inside a High-Reynolds-Number Axial Pump Stage," AIAA Paper 98-0970, 1998.

6. Cho, N-H, Liu, X., Rodi, W., and Schonung, B., "Calculation of Wake-Induced Unsteady Flow in a Turbine Cascade," ASME Paper 92-GT-306, 1992.

7. Swanson Analysis Systems, Inc., "ANSYS Users Manual," Version 5.6, Cannonsburg, Pennsylvania (1999). van Roods, M., Ferber, M.K., Richerson, D.W., eds. Ceramic Gas Turbine Design and Test Experience, ASME Press, 2002.

8. van Roods, M., Ferber, M.K., Richerson, D.W., eds. Ceramic Gas Turbine Design and Test Experience, ASME Press, 2002. 


\begin{tabular}{|c|c|c|c|}
\hline \multicolumn{3}{|c|}{ REPORT DOCUMENTATION PAGE } & $\begin{array}{l}\text { Form Approved } \\
\text { OMB No. 0704-0188 }\end{array}$ \\
\hline \multicolumn{4}{|c|}{ 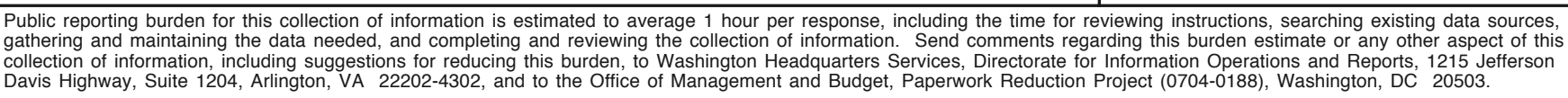 } \\
\hline 1. AGENCY USE ONLY (Leave blank) & $\begin{array}{r}\text { 2. REPORT DATE } \\
\text { March } 2006\end{array}$ & $\begin{array}{r}\text { 3. REPORT TYPE AI } \\
\mathrm{T}\end{array}$ & $\begin{array}{l}\text { ID DATES COVERED } \\
\text { echnical Memorandum }\end{array}$ \\
\hline \multicolumn{3}{|c|}{$\begin{array}{l}\text { 4. TITLE AND SUBTITLE } \\
\text { Fabrication Materials for a Closed Cycle Brayton Turbine Wheel }\end{array}$} & \multirow[t]{2}{*}{ 5. FUNDING NUMBERS } \\
\hline \multicolumn{3}{|c|}{$\begin{array}{l}\text { 6. AUTHOR(S) } \\
\text { Suresh Khandelwal, Chunill Hah, Lynn M. Powers, Mark E. Stewart, } \\
\text { Ambady Suresh, and Albert K. Owen }\end{array}$} & \\
\hline \multicolumn{3}{|c|}{$\begin{array}{l}\text { 7. PERFORMING ORGANIZATION NAME(S) AND ADDRESS(ES) } \\
\text { National Aeronautics and Space Administration } \\
\text { John H. Glenn Research Center at Lewis Field } \\
\text { Cleveland, Ohio } 44135-3191\end{array}$} & $\begin{array}{l}\text { 8. PERFORMING ORGANIZATION } \\
\text { REPORT NUMBER }\end{array}$ \\
\hline \multicolumn{3}{|c|}{$\begin{array}{l}\text { 9. SPONSORING/MONITORING AGENCY NAME(S) AND ADDRESS(ES) } \\
\text { National Aeronautics and Space Administration } \\
\text { Washington, DC 20546-0001 }\end{array}$} & $\begin{array}{l}\text { 10. SPONSORING/MONITORING } \\
\text { AGENCY REPORT NUMBER } \\
\\
\text { NASA TM-2006-214220 } \\
\text { IECEC-2005-5576 }\end{array}$ \\
\hline \multicolumn{4}{|c|}{$\begin{array}{l}\text { 11. SUPPLEMENTARY NOTES } \\
\text { Prepared for the Third International Energy Conversion Engineering Conference (IECEC) sponsored by the American } \\
\text { Institute of Aeronautics and Astronautics, San Francisco, California, August 15-18, 2005. Suresh Khandelwal, RS } \\
\text { Information Systems, Inc., } 21000 \text { Brookpark Road, Cleveland, Ohio 44135; Chunill Hah and Albert Owen, U.S. Army } \\
\text { Research Laboratory, NASA Glenn Research Center; Mark E. Stewart and Ambady Suresh, QSS Group, Inc., } 21000 \\
\text { Brookpark Road, Cleveland, Ohio 44135; Lynn M. Powers, Case Western Reserve University, } 11075 \text { East Blvd, Cleve- } \\
\text { land, Ohio 44106. Responsible person, Albert K. Owen, organization code RPT, 216-433-5895. }\end{array}$} \\
\hline \multicolumn{3}{|c|}{$\begin{array}{l}\text { 12a. DISTRIBUTION/AVAILABILITY STATEMENT } \\
\text { Unclassified - Unlimited } \\
\text { Subject Categorie: } 20 \\
\text { Available electronically at http://gltrs.grc.nasa.gov } \\
\text { This publication is available from the NASA Center for AeroSpace Information, 301-621-0390. }\end{array}$} & 12b. DISTRIBUTION CODE \\
\hline
\end{tabular}

13. ABSTRACT (Maximum 200 words)

A multidisciplinary analysis of a radial inflow turbine rotor is presented. This work couples high-fidelity fluid, structural, and thermal simulations in a seamless multidisciplinary analysis to investigate the consequences of material selection. This analysis extends multidisciplinary techniques previously demonstrated on rocket turbopumps and hypersonic engines. Since no design information is available for the anticipated Brayton rotating machinery, an existing rotor design (the Brayton Rotating Unit (BRU)) was used in the analysis. Steady state analysis results of a notional turbine rotor indicate that stress levels are easily manageable at the turbine inlet temperature, and stress levels anticipated using either superalloys or ceramics.

\begin{tabular}{|c|c|c|c|}
\hline \multicolumn{3}{|l|}{ 14. SUBJECT TERMS } & 15. NUMBER OF PAGES \\
\hline \multicolumn{3}{|l|}{ Brayton cycle; Turbines } & $\frac{13}{16 . \text { PRICE CODE }}$ \\
\hline $\begin{array}{l}\text { 17. SECURITY CLASSIFICATION } \\
\text { OF REPORT }\end{array}$ & $\begin{array}{l}\text { 18. SECURITY CLASSIFICATION } \\
\text { OF THIS PAGE }\end{array}$ & $\begin{array}{l}\text { 19. SECURITY CLASSIFICATION } \\
\text { OF ABSTRACT }\end{array}$ & 20. LIMITATION OF ABSTRACT \\
\hline Unclassified & Unclassified & Unclassified & \\
\hline
\end{tabular}



